\title{
ALGUMAS OBSERVAÇÕES SOBRE O ENSINO METÓDICO NA GEOGRAFIA ${ }^{1}$
}

\author{
CARL RITTER
}

$\mathrm{O}$ valioso artigo Beiträge zu einer bessern und zweckmäßigern Methode für den geographischen Unterricht (Contribuições para um método melhor e mais apropriado ao ensino de Geografia) do senhor Lindner, que encontrei no caderno de abril da Zeitschrift für Pädagogik (Revista de Pedagogia), página 265, incita-me ainda a compartilhar algumas ideias - divergentes daquelas [contribuições] - sobre o mesmo assunto, o qual me parece ser suficientemente importante para examinálo de maneira mais precisa e séria. O próprio senhor autor daquele artigo solicita a investigação de seu método; eu me atrevo a assinalar meus pontos de vista, os quais me trazem um vasto campo para o tratamento desta ciência e, do mesmo modo, peço por exame.

É incontestavelmente muito verdadeiro o fato de que a Geografia [Geographie] possa ser considerada como esta parte do ensino, sobre cujo método ainda não se realizou absolutamente nenhuma unificação geral das ideias. Isto se mostra já a partir da mais superficial avaliação dos meios de ensino, os quais, como em tantas outras disciplinas, são fartos e frequentemente abrangem muita coisa boa, mas mesmo assim não satisfazem, em muitos aspectos, o professor pensador. Também é verdade o que o senhor [p. 199] Lindner observa quanto ao fato de quase não haver nenhuma ciência, da qual não se transmita fragmentos para o interior da Geografia (Geographie). Nela estão concatenadas a Matemática [Mathematik], a História natural [Naturgeschichte], a Tecnologia [Technologie], a História [Geschichte], a Estatística [Statistik], o Estudo do Homem [Menschenkunde]e o Estudo dos Povos [Völkerkunde] etc., cuja conexão pode resultar com freqüência

\footnotetext{
${ }^{1}$ Texto originalmente publicado como Einige Bemerkungen über den methodischen Unterricht in der Geographie, em 1806.

Traduzido por Leonardo Arantes, doutor em Geografia pela Universidade Federal Fluminense, onde foi bolsista CAPES-DAAD em estágio doutoral no Leibniz-Institut für Länderkunde, Leipzig, Alemanha. Revisão do Prof. Dr. Wolf-Dietrich Sahr, do Departamento de Geografia da Universidade Federal do Paraná. Agradeço ao colega Aleikos Stogiannos pela tradução dos termos em grego.
} 
num todo muito colorido. Uma vez que ele denomina este tipo de tratamento de prático, e este lhe parece ser o incorreto, ele desenvolve então a ideia de seu método, no qual a Geografia [Geographie] é tratada como ciência pura [reine Wissenschaft] e sua finalidade é, por conseguinte, determinada. Esta consistiria no seguinte: "denominar o espaço em suas diferentes repartições, fixarmo-nos no mesmo, e apresentar as direções e relações do mesmo umas com as outras de maneira clara e intuitiva."

No entanto, certamente pode-se questionar se a Geografia [Geographie] enquanto ciência poderia ser tratada desse modo puro. A Geografia [Geographie] pertence às ciências históricas [historische Wissenschaften] (no sentido amplo) e compreende, ao lado da Descrição da natureza [Naturbeschreibung], a subdivisão da mesma, a qual se designa ciência descritiva [beschreibende Wissenschaft], em oposição à [ciência] narrativa [erzählende Wissenschaft], à qual pertence a História [Geschichte] (no sentido estrito). A essência destas ciências históricas [historische Wissenschaften] reside no fato de que elas se referem a objetos individuais que são dados na experiência, e não a objetos que podem ser pensados através de conceitos gerais, subordinados e por meio de princípios gerais reconhecidos ou construídos. Elas de fato dividem o campo do conhecimento com as ciências da razão [Vernunftswissenschaften], porém, são empíricas, enquanto as outras são racionais.

[p. 200] A Geografia (Geographie) não pode ser ciência pura,equivalente ao complexo de um conhecimento criado a partir de princípios racionais e não a partir da experiência. Tão pouco pode haver uma História [Historie] pura. As ciências puras e racionais [reine und razionale Wissenschaften] partem de conceitos gerais etc.; as ciências históricas [historische Wissenschaften], todavia, partem de objetos individuais da percepção e buscam unificá-los num todo. As ciências racionais [razionalen Wissenschaften] nos conduzem da teoria à experiência; as [ciências] históricas [historische Wissenschaften] da experiência à teoria. Somente quando Euclides e Sócrates, através de uma conexão lógica, trouxeram seus conceitos independentes da experiência para dentro do sistema, somente a partir de então nós podemos falar da Matemática [Mathematik] e da Filosofia [Philosophie] enquanto ciências; já antes, porém, Heródoto havia publicado sua obra-prima sem teoria, tal como a experiência lhe havia trazido os dados históricos individuais. Nós não podemos distorcer a necessária marcha do conhecimento científico, a qual é a mesma em nações inteiras bem como em indivíduos. A Geografia [Geographie] é então um conhecimento criado a partir da experiência, e nisso se funda a afirmação de que seu método de ensino deva ser absolutamente oposto aos métodos das ciências racionais [razionale Wissenschaften].

Se o senhor Lindner compreende por Geografia pura [reine Geographie], tal como me parece, provavelmente apenas aquilo que pertence à essência da mesma, deveríamos tentar sobretudo perspectivar o essencial da mesma. Conforme o prefácio, a Geografia [Geographie] seria para ele: "A arte de desenhar a Terra com 
linhas". Mas por que com linhas? O primeiro, por quem esta expressão [p. 201]

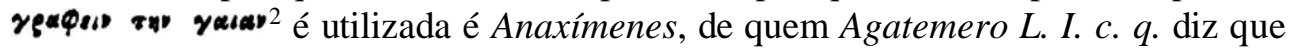
ele projetou pela primeira vez um mapa das partes habitadas da Terra (

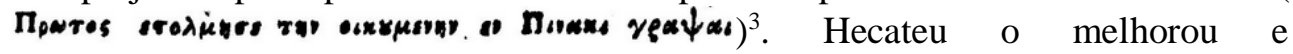
acompanhou-ode uma explicação escrita. Se isto deve ter sido então apenas uma simples rede de mapas regionais [Landkartennetz], tendo em conta que aí Anaximandro parece não ter ensinado nada ainda da Terra enquanto globo, $(\boldsymbol{\gamma} \boldsymbol{\varphi})^{4}$

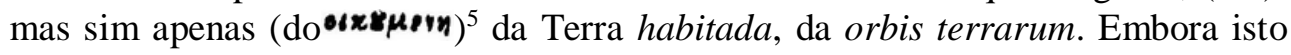
seja também o significado etimológico original, deveríamos compreender então por Geografia [Geographie], por Descrição da Terra [Erdbeschreibung] a mesma coisa? ${ }^{6}$ Seria esta, para nós, apenas o conhecimento da quantidade da Terra, ligada a sua denominação, como diz o senhor Lindner?

A Geografia [Geographie] se refere de fato aos objetos corpóreos individuais, os quais existem fora de nós e de maneira simultânea [nebeneinander]; por este motivo, contudo, a ciência das relações espaciais [Wissenschaft der räumlichen Verhältnisse] destes objetos não existe sozinha, assim como a História [Geschichte] sozinha não é a ciência das relações cronológicas. A Cronologia [Chronologie] é apenas condição necessária da História [Geschichte], mas não sua essência mesma, [p. 202] a qual reside no pragmático dos acontecimentos no âmbito destas relações de tempo. Portanto, assim como a Cronologia [Chronologie] não cria, ao lado da denominação dos objetos históricos mais importantes, a essência da História [Geschichte], tampouco a Geografia matemática [mathematische Geographie] juntamente com a Corografia [Corographie] e a Topografia [Topographie] ou a denominação dos lugares e regiões [Länder] criam a essência da Geografia [Geographie]. A Cronologia [Chronologie] e a Geografia matemática [mathematische Geographie] são apenas ciências auxiliares para o estudo histórico, e o tópico ou a denominação dos objetos é mera nomenclatura.

Se se quiser considerar a Geografia [Geographie], neste sentido, absolutamente como ciência pura [reine Wissenschaft], também aqueles exercícios matemáticopropedêuticos preliminares deveriam então ser excluídos, porquanto estes, a rigor, compõem nada mais que uma parte da Geometria [Geometrie] aplicada à superfície da Terra.

\footnotetext{
2 "Descrever a Terra"

3 "O primeiro que ousou descrever o ecúmeno registrando-o numa tábua"

4 "Terra"

5 "Ecúmeno"

${ }^{6}$ Tudo depende basicamente disso. Se acharmos necessário criar, a partir daquele termo, o conceito de Geografia [Geographie], outra pessoa pode talvez desenvolvê-lo com mais justeza a partir do termo alemão: Descrição da Terra [Erdbeschreibung]; mas ela certamente não entenderá esta denominação desta maneira, dado que com o descrever ela não pensa o enquadramento da superfície do globo terrestre com linhas, mas sim que agora ela as tomará tal como é usada a palavra descrição aplicada a objetos da natureza.
} 
Entretanto, também os exercícios matemáticos preliminares indicados, os quais devem partir da esfericidade da Terra, não bastam para fundar esta Geografia pura [reine Geographie], posto que os conceitos de horizonte e de firmamento devem ser aplicados apenas na esfera terrestre para compreendê-la. À Geografia [Geographie] deveria necessariamente anteceder, portanto, apenas uma Uranografia [Uranographie], a qual, todavia, deveria ser rejeitada, por boas razões, enquanto uma ciência elementar ${ }^{7}$.

Por estas razões, a mim não me parece provável que o método indicado possa ser então o mais apropriado [p. 203] para o ensino elementar ${ }^{8}$. A marcha do método para todas as ciências históricas não pode ser analítica; ela deve ser sintética9.

Esse método indicado não me parece ser também criativo, porque ele quer tratar apenas da quantidade e não também da qualidade e da relação de seu objeto. E este é o segundo ponto sobre o qual eu me atrevo a compartilhar algumas observações.

A ciência de todas as relações quantitativas é a doutrina das grandezas [Größenlehre] referente ao espaço e ao tempo; a parte tópica da Geografia [Geographie] é nomenclatura; o que ainda resta então como o característico da ciência comum; o que é Geografia [Geographie]?

A descrição do atual (na medida em que falamos aqui apenas da Geografia moderna) estado de coisas da Terra considerada, em todas as suas relações, como parte do universo e como todo para si. Sua relação com o universo é tratada pela Geografia matemática; a descrição referente a ela própria decompõe-se em duas partes, até o ponto em que [p. 204] seu estado (aqui trata-se clara e restritamente da superfície) é um produto da natureza ou da arte. Com o conhecimento da primeira parte ocupa-se a Geografia física [physische Geographie]. Poder-se-ia denominar a segunda parte ou a descrição das relações culturais da superfície terrestre de Geografia econômica [ökonomische Geographie] e lecioná-la separadamente enquanto tal ou unificada com a outra.

Mas apenas na medida em que um objeto está numa certa relação conosco, ele nos pode ser importante; a superfície terrestre [Erdoberfläche], portanto, na medida em que é a morada e escola do mundo animal e do homem e palco de sua atividade. A conexão entre o modo como ela [a superfície terrestre] age sobre ele [o homem] e de como ele retroage sobre ela é, por conseguinte, do mesmo modo parte necessária desta ciência, e gostaria de denominá-la, diante da carência de um nome melhor, de parte zoológica da mesma.

\footnotetext{
${ }^{7}$ Estou inteiramente de acordo.

8 Para mim, também, atualmente ainda não, porquanto a superfície terrestre fragmenta áreas semelhantes, segundo as 6 zonas e 36 meridianos, em 216 retângulos indicados pelo senhor Lindner. Não deveriam os pequeninos poder conseguir um caminho mais fácil para a construção da representação total da Terra e, de fato, sem prejuízo ao exercício de suas capacidades mentais?

${ }^{9}$ Este poder e dever poderia ser questionado em algum ponto de vista.
} 
Se uma separação dos objetos do ensino geográfico deve acontecer, cairia bem aqui o recorte do ensino elementar, ou antes, do primeiro curso de Geografia [Geographie]. Pois uma vez que a Descrição da Terra [Erdbeschreibung] nos é importante apenas do ponto de vista do homem, não o homem considerado apenas como indivíduo, mas sim também enquanto povos e nações, a ciência inteira deve se modificar conforme estes quadros e, assim, se separa neste ponto necessariamente aquela Geografia natural [natürliche Erdbeschreibung] da Geografia civil [bürgerliche Erdbeschreibung], ou antes, Erdkunde [Estudo da Terra].

Esta segunda parte, a qual me parece inteiramente adequada a compor o segundo curso na Geografia [Geographie], [p. 205] é a parte aplicada da primeira a regiões [Länder] e povos e, por este motivo, é chamada de Estudo dos Povos [Völkerkunde] e Estudo Regional [Länderkunde]. Ela contém, além da nomenclatura tópica, o retrato da influência daquelas partes, as quais pertencem à Geografia natural [natürliche Erdbeschreibung], sobre a indústria, o comércio, a cultura e as relações civis das regiões [Länder] e povos no atual estado de coisas.

Esta controvérsia do conceito de Geografia [Geographie] nos conduz para algumas considerações sobre o tratamento e o método desta ciência mesma.

Sua finalidade é tornar conhecido, no singular e no geral, o homem juntamente com o palco de sua atividade; por este motivo, ela é descrição deste palco, não em si, mas sim em relação com o homem. Isto é então a causa inteiramente natural do por que ela intervém no âmbito de quase todos os conhecimentos práticos. Recriminá-la por isto significa aniquilar sua essência. Enquanto não puder ser contestado que a localidade [Localität] tem a influência mais decisiva sobre todos os três reinos da natureza, sobre o ganho de produtos naturais, elaboração e distribuição dos mesmos, assim como sobre a constituição do corpo e sobre a instalação confortável dos homens, sobre sua unificação possível ou real enquanto povos, Estados; [enquanto não puder ser contestado que a localidade] tem a influência mais decisiva sobre aceleração ou retardamento de sua cultura física, intelectual e moral - eu digo, enquanto isto não puder ser contestado, não poderá ser atribuído à Geografia [Geographie] absolutamente nenhum campo mais delimitado.

[p. 206] Por outro lado, ela é o vínculo entre natureza e mundo humano, de ambos indissociável, posto que ela é a condição primeira e mais necessária para a caracterização dos dois. Eu afirmo: é completamente impossível apresentar, de maneira satisfatória, algum destes três objetos - Geografia [Geographie], História natural [Naturgeschichte] e História [Geschichte] com Estudo dos Povos [Völkerkunde] - avulso dos demais. Em cada passo que dermos nesta trajetória monástica limitada, ansiaremos mil vezes por movimento livre do espírito. E se este desejo ansiado não for realizado, seguiremos seu caminho como um recado cujo alvo está no final; não caminharemos prazerosamente na natureza, onde coração e espírito se abrem à riqueza circundante e onde consideramos o caminho 
mesmo como fim, ficando o objetivo, no entanto, cada vez mais distante. Não devemos pensar estas ciências como deusas que caminham a certa distância uma da outra, timidamente em sua área, em três rotas escondidas; elas são irmãs da mesma forma e caminham de braços dados para um objetivo, o universo, e apenas conseguem alcançar este objetivo superior com forças unificadas.

Como seria possível caracterizar também apenas os primeiros conceitos da Topografia [Topographie], por exemplo, o que são água e terra, terra firme e mar, montanha e chapada, altitude e vale, rocha e penhasco, fonte e córrego, rio e correnteza etc., sem explicação com base na doutrina da natureza; o que é fértil e infértil, rochoso, barroso, arenoso, o que é terra de jardim, turfa, aptidão e inaptidão do solo, como caracterizar as cadeias montanhosas, sem falar de sua forma e conexão e de suas componentes que são as condições destas formas, [p. 207] sem explicações com base na Mineralogia [Mineralogie]? Como seria possível falar sobre produtos de uma terras em pressupor ou compartilhar conhecimentos com base em todos os três reinos da natureza; como falar sobre ganho e elaboração destes produtos sem conhecimento da Tecnologia [Technologie]? A mim parece-me incompreensível o modo como se quis dar representações claras sobre todos estes conhecimentos elementares da Geografia [Geographie] sem intervir no âmbito da História natural [Naturgeschichte] e, do mesmo modo, ao contrário, partindo da História natural [Naturgeschichte] (deveríamos colocar sua essência na Descrição da natureza [Naturbeschreibung]) sem fazer referência à Geografia [Geographie]. Do mesmo modo será impossível falar sobre habitantes da Terra sem intervir mais ou menos no âmbito da História [Geschichte] e, ao contrário, não falar sobre acontecimentos históricos sem olhar de volta para a superfície terrestre [Erdoberfläche].

Essas observações se dirigem para o fato de que o método mais natural seja mesmo aquele que saiba unificar todos esses múltiplos objetos dentro de um todo, e então é este também que, conforme a natureza do objeto, conduz do singular para o geral. É ele que primeiramente orienta a criança na realidade e busca fixar que o lugar onde ela vive também ensina a ver. Que seja então a cidade ou a vila, a montanha ou o vale, onde a criança possa obter seus primeiros conhecimentos geográficos, não em sala de aula, no mapa e a partir do livro, mas sim na natureza; isso permanece imutável. Este método elementar unifica todas as exigências da ciência e do método, e é por este motivo o único. Aqui a criança conhece a região [Land] em todas as suas relações, aprende [p. 208] a compreender o mapa de todas as outras regiões [Länder] na imagem daí registrada por si própria. Se esta formação elementar for concluída de maneira apropriada, as maiores dificuldades que a Geografia [Geographie] oferece enquanto ensino mais 
distanciado ${ }^{10}$ serão superadas. Eu a dividiria em apenas dois cursos.

Primeiro curso: Geografia natural [Natürliche Erdbeschreibung]. Com esta eu levo em consideração as doutrinas propedêuticas mais simples e mais necessárias a partir da Geografia matemática [mathematische Geographie], assim como os exercícios matemáticos preliminares com circulos, esferas e cubos, sobre os quais o senhor Lindner, em seu artigo, deu mais excelentes acenos. Mas, prosseguindo, eu não seguiria seus exercícios até o ensino das zonas. Todas as outras partes do constructo matemático deixaria aos cuidados da parte aplicada da Matemática [Mathematik], a qual teria de lidar com isto ex professo. Apenas se já fosse pressuposto ao aluno algum conhecimento de Geometria [Geometrie], eu daria então um passo adiante em relação ao senhor Lindner e, em algumas zonas terrestres que pudessem ser transformadas em um polígono retilíneo, tentaria a medição dos triângulos aí contidos. A escala deveria ser o grau do Equador, e para o tipo de projeção deveria ser escolhida aquela que, do ponto de vista da apresentação do plano, menos divergisse da forma esférica. A primeira tentativa seria fazer com um mapa especial da região [Land] (segundo uma escala maior) que a gente mesmo habitasse. Isso seria bem necessário para obter,em certa medida, um ponto de comparação para as relações de grandeza: pois apenas aquele que aprende a julgar distâncias através de grandes viagens obterá então, no fim, clareza e determinidade.

[p. 209] Ao invés de armar então uma rede matemática constituída a partir de retângulos como que sobre o plano da Terra [Erdfläche], eu determinaria tudo, única e exclusivamente para a fixação do tópico, por meio dos recortes naturais da superfície terrestre. Pois esse orientar-se através de graus de longitude e latitude é fértil absolutamente apenas para a Geografia matemática [mathematische Erdbeschreibung], de modo algum influente nas demais partes da mesma, permanecendo, para estas, sempre apenas um fundamento aleatório de divisão. $\mathrm{O}$ orientar-se sobre o plano da Terra [Erdfläche] segundo os recortes naturais, os quais ela própria nos apresenta é, ao contrário, extremamente fértil para a Geografia [Geographie] e todas as ciências a ela relacionadas, e uma operação que engendra no espírito a imagem determinada da própria Terra. Os recortes naturais, os quais conhecemos exatamente por esse intermédio, compõem ao mesmo tempo a base de toda a Geografia política [politische Geographie], a qual, aplicada a eles, torna-se capaz, em primeiro lugar,de um tratamento pragmático em geral ${ }^{11}$.

10 Por "ensino mais distanciado" [fernerer Unterricht] pode-se entender aqui: 1) o ensino de Geografia em sala de aula (e não na natureza, tal como Ritter, seguindo Rousseau, Pestalozzi, Salzmann e Guts Muths defende); 2) o ensino subsequente aos ensinamentos básicos dados junto à natureza; ou 3) o ensino geográfico de lugares mais distantes, nos quais não se teria condições de levar os alunos [N.T.].

${ }^{11}$ Estou completamente de acordo. Além dos motivos indicados pelo autor, este método já me parece, por isto, preferível, porquanto ele ajuda mais à intuição do aluno do que o tipo de recorte por linhas. Isto pode ser facilmente visto, posto que esse tipo de recorte natural, em todas as suas divisões, oferece à faculdade de representação do aluno uma rica matéria para o exercício, na medida em que 
As delimitações através demares compõem aqui os primeiros recortes: terra firme e ilhas. Os recortes [p. 210] do mar são oceanos, costas oceânicas, mares mediterrâneos; os sub-recortes são golfos, baías, portos, enseadas, desembocaduras, canais e estreitos.

$\mathrm{Na}$ terra as delimitações são os divisores de água através de cordilheiras ou elevações; seus sub-recortes são, neste caso, as cadeias de montanhas extensas com seus troncos, ramos, nivelamentos e sopés.

Essas recortam todo o plano da Terra [Erdfläche] de maneira mais determinada em grandes regiões fluviais [Flussgebiete] dos mares à primeira vista existentes; as quatro direções sempre dão quatro recortes destas regiões fluviais, a vertente norte, a leste, a sul e a vertente oeste; os rios formam distritos fluviais [Flussdistricte]. $\mathrm{O}$ que não pertence a nenhuma região fluvial de um mar é uma região encravada [Binnenland]. Assim, toda a superfície terrestre [Erdoberfläche] está repartida de maneira mais exata, segundo suas leis próprias, em continentes físicos, bacias e distritos. Quão importante esta operação é para a formação da visão e para o próprio conhecimento da Terra, prefiro nem comentar; mas ela tem também a maior influência sobre o próprio ensino geográfico. Pois as mesmas leis da delimitação continuam a atuar ininpterruptamente sobre as propriedades características do clima, dos tipos de montanhas, do arranjo do solo e, portanto, também dos produtos mineralógicos, do mundo vegetal e do mundo animal de cada região [Gebiet] e seus distritos. Considera-se deste ponto de vista apenas, por exemplo, a região fluvial do Mar Báltico, do Mar do Norte, do Mar Mediterrâneo, do Adriático e de outros. E mais. A mesma influência mostra-se então também sobre os habitantes destas regiões naturais (natürliche Ländergebiete):pois eles vivem sob a mesma influência do clima, têm o mesmo [p. 211] gênero alimentício; com eles desenvolve-se de maneira semelhante a manufatura, a agricultura e a navegação; mesmo no caráter e em suas relações culturais eles terão de certo modo algo em comum, a depender do local. Através desta marcha, não deveria poder tornar-se o estudo da Geografia [Geographie] bastante simplificado e classificado de maneira mais científica (isto é, segundo suas leis internas, não segundo instituições positivas)? Se a superfície da Terra for então conhecida singularmente segundo este ponto de vista, os resultados poderão ser unificados e considerados pelos próprios alunos sob pontos de vista gerais. Tente este caminho e ficará admirado com os notáveis resultados, e compreenderá tranquilamente a simplificação junto ao ganho deste caminho. Ainda não temos nenhum recurso especial, nenhum mapa e nenhum livro didático que seja elaborado para este curso. Entretanto, isto também não é mesmo tão necessário, uma vez que a própria elaboração de mapas regionais [Landkarten] é necessidade tanto do professor como do aluno de Geografia [Geographie] e, deste modo, cada um mesmo pode

aquele recorte linear é pobre nisso, e na maior parte das vezes parece poder tornar-se apenas objeto de memorização. 
confeccionar o imprescindível, muito embora isto não possa ser conseguido ao lado das mais sobrecarregadas atividades dos professores. Uma pequena contribuição para esses recursos deste curso aparece sob o título: Sechs Karten von Europa mit erklärendem Texte u.s.w. ein Hilfsmittel beim Unterrichte in der Erdbeschreibung. Schnepfental in der Buchhandlung der Ersziehungsanstalt (Seis Mapas da Europa com Texto Explicativo etc., um Recurso para o Ensino na Geografia. Schnepfenthal, Editora do Educandário ${ }^{12}$ ), no qual a Europa é apresentada no modo indicado dentro de suas relações principais ${ }^{13}$.

[p. 212] Ao lado deste curso encontra-se o ensino de História natural [Naturgeschichte] como uma ciência a ser ensinada simultaneamente - todavia, em um outro horário -a qual do mesmo modo terminassenocaminho da intuição, dentro do próprio lugar e posição onde o aluno vive, sua formação elementar.Tal como a Geografia [Geographie] caminha de continente em continente, aquela pode e deve andar ao lado desta; ambas se apoiarão também da maneira mais interessante. Então, se os resultados gerais sobre as relações das regiões [Länder] forem unificados, isto também acontecerá com os corpos da natureza, cujo panorama do mesmo modo será unificado num todo através de um sistema natural [natürliches System].

Segundo Curso: Geografia política [Politische Erdkunde]. Aqui, apenas a Geografia positiva [positive Geographie], a qual depende das instituições do homem, deveria ser lecionada. Então o aluno aprenderia a registrar sobre a superfície real da Terra os reinos, ducados, as províncias e circunscrições, seus nomes e fronteiras. Ele obterá, assim, um conceito do que a natureza e do que os homens fizeram; encontrará tranquilamente as causas das formas, e aí, onde estas não estão de acordo com o arranjo da natureza, ele as buscará em relações e condições especiais (apenas ensaie isto em mapas; numerosas guerras, tratados de paz, instituições políticas etc. têm nisso seu fundamento). [p. 213] O reino inteiro em suas relações principais com todas as divisões e a diferencialidade de seu solo, seu clima, e com isto também de seu plantio, de sua cultura, de seus habitantes, de sua quantidade de cidades, suas forças principais etc. lhe ficará evidente. O aluno se habituará com o ponto de vista filosófico de que a terra [Land] não está ligada ao Estado, mas sim o Estado à terra; de que tudo que está nele, está modificado da maneira mais determinada. Logo, a grande visão de mundo [Weltsansicht] de pensar o detalhe não enquanto detalhe, mas sim em relação com o todo, o olhar dentro do universo é preparado por essa marcha, e não o sentido acanhado, mortífero ao espírito, de considerar tudo por obra humana ao invés da ordem universal superior.

\footnotetext{
${ }^{12}$ A título de exemplificação, anexamos ao final um dos mapas contidos na mencionada obra [N.T.].

${ }^{13}$ Quem gentilmente conhece o autor, tal como o conheço, não entenderá esta citação de seu próprio trabalho de maneira equivocada [p. 212] e não a interpretará como egoismo. Posso dar testemunho aos seis mapas de que estes são um recurso muito útil no ensino geográfico.
} 
Esse caminho é ao mesmo tempo o único, verdadeiramente preparatório, que conduz ao estudo espirituoso da História [Geschichte], da História da formação do espírito humano sob as diferentes zonas, através de todos os séculos (neste sentido, consulte detalhadamente, por exemplo, as ideias de Heeren sobre política e circulação dos Estados antigos), sendo mesmo necessário para a História [Geschichte] das guerras e batalhas.

Ele é de longe o único que nesta última década ainda pôde ser trilhado junto às inúmeras trocas de Estados, regiões [Länder] e províncias sem causar alguns transtornos nas cabeças dos principiantes.

Uma vez que o aluno registrou então em seu mapa as novas e mais recentes mudanças de limite de uma região [Land] [p. 214] ou mesmo estabeleceu comparação com esse [limite], ele será conduzido para o modo como o homem utiliza suas vantagens naturais para a indústria e o comércio. Na minha opinião, com este ensino deveria convergir, simultaneamente, o ensino científico da Tecnologia e do Estudo da Manufatura (isto é, em um outro horário, apenas no mesmo período que o de cima), para cuja formação elementar o fundamento estava igualmente colocado no lugar e posição.

$\mathrm{O}$ ensino, afirmo, deve se expandir continuamente também sobre o homem enquanto o objetivo último de cada ciência e encerrar como Estudo dos Povos [Völkerkunde]. Objeta-se aqui contra o fato de que este objeto conduz o aluno para dentro de um campo inteiramente estranho, e que o Estudo dos Povos [Völkerkunde] pressupõe o Estudo do Homem [Menschenkunde].

O primeiro ponto é em certa medida verdadeiro, se a Geografia [Geographie] for apenas o conhecimento da Terra em si; mas se ela fizer referência ao homem, então eu não vejo como o Estudo dos Povos [Völkerkunde] possa ser estranho a este ensino, uma vez que a distribuição dos povos, população e caráter nacional são assim caracterizados de maneira determinada pelo local (veja sobre isto o mapa dos povos da Europa, um daqueles seis anteriormente indicados). Mas este ensino, sem dúvida, pressupõe o Estudo do Homem [Menschenkunde]. Destarte, o que o Estudo do Homem [Menschenkunde] pressupõe? O Estudo da Alma [Seelenkunde $]^{14}$; e este? Filosofia e experiência etc. Pode-se fazer essa objeção em todos os casos semelhantes; ela comprova apenas o entrelaçamento de todos os nossos conhecimentos. $\mathrm{O}$ aluno que atingiu esta classe, deve ter obtido elucidação própria sobre si mesmo; [p. 215] pode então, tranquilamente, passar de suas contemplações sobre os fenômenos externos para o homem e deste para aqueles, o que ele, em todo caso, faz mesmo diariamente. Só se pode falar aqui do caráter nacional ou, se se preferir, do peculiar das nações, não de padrões morais e intelectuais em que elas se encontram. Não é tão difícil compartilhar aquele [caráter nacional] com o aluno, na medida em que isto se refere à constituição do corpo, ao temperamento, ao modo de vida, costumes, habilidades, brincadeiras, disposições, representações

\footnotetext{
${ }^{14}$ Por Estudo da Alma [Seelenkunde] entenda-se aqui, de certo modo, a Psicologia [N.T.].
} 
religiosas. Nem mesmo quanto a estas últimas, já que em poucas nações civilizadas elas estão sempre acompanhadas dos modos de representação abstraídos da natureza local sensível circundante. Com este Estudo dos Povos [Völkerkunde], parece-me necessário que algumas informações históricas sobre distribuição, miscigenação e descendência das matrizes dos povos devam ser indicadas para obter elucidação sobre o lugar de morada [Wohnort] do povo, sua quantidade de pessoas, suas relações culturais (se ele é reprimido ou é repressor) e sua língua. Como este [povo] também se relaciona com o local, veja a tábua dos povos ${ }^{15}$ mencionada acima.

Mas se se quiser afirmar que estes objetos em geral, tantos quanto possíveis, devam ser lecionados na aula de maneira particular e separada (como, por exemplo, um Estudo dos Povos (Völkerkunde) próprio distinto de todos os outros: pois este não pode ter espaço também na História contemporânea (neueste Geschichte)), com isto eu não posso estar de acordo. Este separar reside apenas em nós; tudo existe numa conexão necessária dentro da realidade, e esta conexão nós nunca podemos compreender por meio de separação do múltiplo. Contudo, dois caminhos seguros nos conduzem [p. 216] para o objetivo. O exercício do espírito pelas ciências racionais (razionale Wissenschaften) consiste no abstrair, no separar do uno; o exercício do espírito pelas ciências descritivas (beschreibende Wissenschaften) e [pelas ciências] narrativas (erzählende [Wissenschaften]) [consiste] no apreender do múltiplo. Para lecionar aquelas convém o raciocínio; para lecionar estas a arte da apresentação. Aquelas pressupõem a capacidade de reconhecer; estas de apreender. Naquelas reside o ato da inteligência; nestas da intuição. Com aquele o ânimo é espontâneo; aqui é receptivo. Ambas são necessárias, indispensáveis para o conhecimento. Se procedermos contra estas leis existentes na natureza do espírito, nunca poderemos conseguir uma metodologia aprimorada. E essa crítica atinge aquela [metodologia] que trata tudo conforme uma lei; ela deve ser feita àquela [metodologia] que busca transpor o método do suíço imortal ${ }^{16}$ a todas as ciências, promovendo-se, através disso, a mesma unilateralidade da formação da faculdade do conhecimento, a qual Pestalozzi acusou, com razão, de mero ensino extensivo do conhecimento, que o poeta $V o \beta$ fez de novo ao Real-ensino em sua espirituosa recensão do Plano escolar da Bavária.

Mas não sei por que não se pode consentir nessas ciências, tratadas segundo seu método, absolutamente nenhum meio para a formação formal do espírito. Ela é

\footnotetext{
${ }^{15}$ Ritter se refere aqui ao "mapa dos povos" [Völkerkarte] (em anexo) por ele próprio produzido e anteriormente citado, e não ao assim chamado "painel [ou quadro] dos povos" (Völkertafel) produzido por volta de 1725 por um pintor desconhecido oriundo do atual estado autríaco da Estíria (Steinmark). Ver Engelmann, Gerhard. Carl Ritters Sechs Karten von Europa. Erdkunde, 1966, vol. 20, p.104-110 [N.T.].

${ }^{16}$ Ritter refere-se aqui ao autor de Émile, ou De l'éducacion, o genebrino Jean-Jacques Rousseau (1712-1778).
} 
considerada absolutamente apenas como servente no âmbito do saber humano, que apenas existe para suprir o armazém da memória, tal como uma farmácia com uma Materia medica, a qual costuma ser utilizada apenas em momentos extraordinários da vida, mas que fundamentalmente não pertence de modo algum às necessidades [p. 217] da vida humana. Não há inúmeros contadores que não conseguem nenhuma formação formal por meio de suas ciências, inúmeros adeptos de sistemas filosóficos que não se tornaram filósofos? Aqui a ciência ou o método da ciência pode ser acusado? Do mesmo modo, quantos repertórios históricos vivificantes, quantos colecionadores de espécies não existem sem que eles sejam historiadores ou naturalista?

Defendo que as ciências representativas [darstellende Wissenschaften $)^{17}$, tratadas como objetos de ensino, formam de maneira igualmente intensa as faculdades do espírito.

Kant diz (Antropologia, p. 22): "Vê-se bem que, se a faculdade do conhecimento em geral quer dizer entendimento, este deve conter a faculdade de apreensão (attentio) das representações dadas para forjar a intuição do objeto; deve conter a faculdade de abstração (abstractio) para forjar o conceito do objeto; deve conter a faculdade de reflexão (reflexio) para forjar o conhecimento do objeto." Esta capacidade de apreensão constitui então o que é formado de maneira intensa e que é do mesmo modo necessário para a reflexão, enquanto faculdade de abstração. Esta faculdade de apreensão ou esta receptividade do homem interior é o que o torna capaz de poder perceber alguma coisa, a qual torna possível o ato da apreensão. E a execução deste ato, ligado à reflexão, deve ser concluido na alma. A capacidade (e isto não é de certo modo nenhuma capacidade, porquanto nós a chamamos, em oposição à atividade espontânea, de passiva e sofredora), que é a condição deste ato, deve ser capaz de uma [p. 218] formação intensiva ou formal. Os meios de formação formal desta capacidade são as ciências representativas [darstellende Wissenschaften]. Se até então não se a utiliza enquanto tal, não é sua culpa (individualmente isto foi feito); assim, por este motivo, é incorreto considerá-las apenas como ciências auxiliares no ensino de jovens.

Ambos os meios de ensino, as ciências racionais [razionalen Wissenschaften] e as ciências representativas [darstellenden Wissenschaften], deveriam juntas, portanto, proporcionar ao homem uma formação harmônica de si próprio, caso ele não deva viver no mundo das ideias ou no mundo empírico, mas sim conseguir uma formação completa de sua faculdade de conhecimento.

Denomino pragmática a marcha do método dessas ciências- enquanto meio de formação formal - para expressar o "um por meio do outro" [eins durch das andere], não "um ao lado do outro" [eins neben dem andern], porquanto não

\footnotetext{
17 Por ciências representativas [dartstellende Wissenschaften] Ritter compreende tanto as ciências descritivas [beschreibende Wissenschaften] como as ciências narrativas [erzählende Wissenschaften], distintas das chamadas ciências racionais. Ambas estão ligadas à "arte da apresentação" [Kunst der Darstellung] acima mencionada pelo próprio autor [N.T.].
} 
encontro nenhuma palavra melhor para isto. Compreendo assim a apresentação do múltiplo para um todo contínuo e permanente do ponto de vista da amplitude e do conteúdo.Cada uma dessas ciências individuais é capaz de um modo de tratamento pragmático (mesmo sendo também dentro de um círculo ainda muito especialmente delimitado) e, por sua vez, o modo de tratamento pragmático de tudo forma a grande visão de mundo [Weltansicht], a qual está do mesmo modo tão afastada da erudição de sala de aula e da superficialidade quanto a sabedoria universal está do cisma metafísico e do senso comum.

Ritter, Educador em Frankfurt sobre o Meno. 


\section{Anexo}

Painel sobre os Habitantes da Europa, sobre a Quantidade de Povos e a População deste Continente

(Tafel über die Bewohner von Europa, über Volksmenge und Bevölkerung dieses Erdtheils)

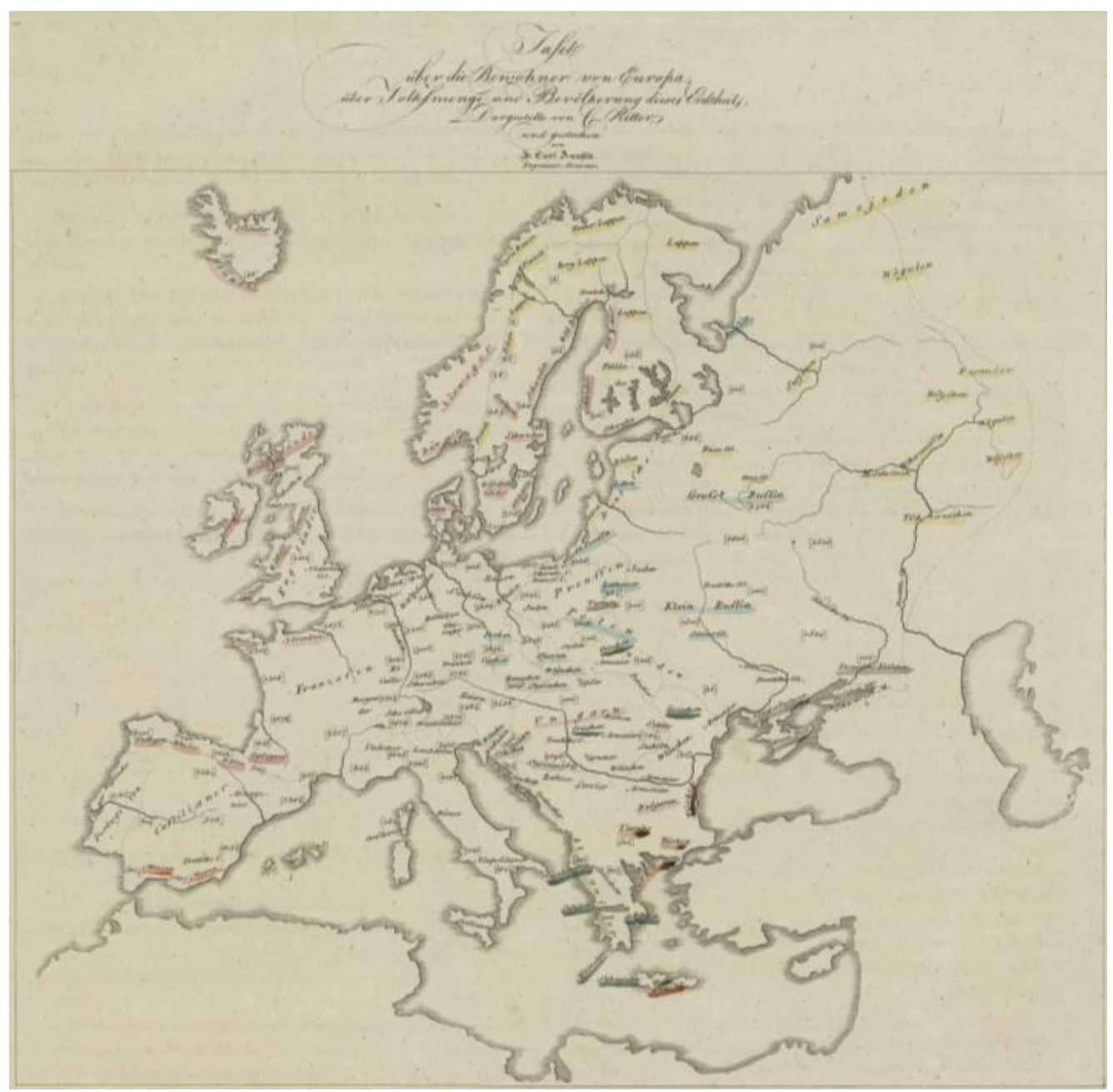

Fonte: RITTER, Carl. Sechs Karten von Europa, Schnepfenthal, Buchhandlung der Erziehungsanstalt, 1806, p. 20 (Disponível em: <online em: http://gdz.sub.unigoettingen.de/dms/load/img/?PPN=PPN685782352\&amp;IDDOC=877627>). 